\title{
ON THE ACCURACY OF THE MINERAL ANALYSIS PERFORMED BY ELECTRON MICROPROBE
}

\author{
JaAk Ko Sivvola \\ Geological Survey of Finland, Otaniemi, Finland
}

\begin{abstract}
In the first part of the paper theoretical principles of the electron microprobe analysis are reviewed. Stress is laid on the absorption correction which is discussed in greater detail.

The second part deals with a series of measurements demonstrating the magnitude of the absorption correction and the accuracy of the final results. The analyses were performed using both oxide and silicate standards. The results were calculated applying Philibert's primary absorption correction term. Comparing the results with those of wet chemical analysis the following limits for the accuracy (in percent) of microprobe analysis are obtained: $\mathrm{SiO}_{2} \pm 0.9$, $\mathrm{Al}_{2} \mathrm{O}_{3} \pm 0.4, \mathrm{Fe}_{2} \mathrm{O}_{3} \pm 1.5, \mathrm{MgO} \pm 0.5$ and $\mathrm{CaO} \pm 0.7$. Furthermore, the measurements indicate that when analysing small concentrations in silicate minerals using a silicate standard, there is a line a r relationship between the recorded $\mathrm{X}$-ray line intensity and the concentration to be analysed.
\end{abstract}

\section{Introduction}

The electron microprobe analysis is a widely used analytical method in both geological and metallurgical investigations. It is most commonly employed to analyse the qualitative compositions of different kinds of samples. This is understandable because of the great ability of the microprobe to display the electron and the $\mathrm{X}$-ray images with high resolving power. Another important function of the microprobe is the quantitative analysis of specimens. The high resolution and the non-destructive nature of this method renders it well adapted to chemical analyses.

In the first part of this paper the principles of the correction procedure necessary in the quantitative electron microprobe analysis are reviewed. The main purpose is to show the reader the general considerations and the basic theories are omitted. Only the absorption correction is discussed in more detail.

The second part presents quantitative microprobe analyses of the main components, $\mathrm{SiO}_{2}$, $\mathrm{Al}_{2} \mathrm{O}_{3}, \mathrm{Fe}_{2} \mathrm{O}_{3}, \mathrm{MgO}$ and $\mathrm{CaO}$, of 13 silicate minerals and glasses. Also a short series of $\mathrm{MnO}$ analyses is presented in order to show the possibilities of analysing small concentrations quantitatively. In correcting the results, stress was laid on the absorption correction. The fluorescence and the atomic number corrections are less important when analysing silicate minerals with suitably chosen standards. The results are presented in the form of tables and graphs.

The possibilities and difficulties of this analytical method may not yet be generally known in the fields of natural and technical sciences. This 
paper is intended to give the reader an idea about the practical accuracy which can be reached in routine microprobe analyses applied in geological investigations.

\section{PART I}

\section{The electron microprobe}

The electron microprobe is an instrument in which the sample is bombarded by finely focused electron beam (Fig. 1) ${ }^{1}$. Using a two lens electron optical system it is possible to diminish the beam diameter to approximately 1 micron. Characteristic X-rays of the elements present in the specimen originate due to collisions of the primary electrons with the atoms of the target elements. The X-ray spectra are analysed using crystal monochromators and/or proportional counters. When this is performed for w a $\mathrm{ve}$ $\mathrm{le} \mathrm{ng} \mathrm{th}$ a qualitative analysis results. It is possible to make runs on a selected spot, line or area whence the corresponding element distributions are obtained. With the aid of the modern instruments a qualitative determination can be performed in the range of atomic numbers 5 92 or from boron to uranium. If the characteristic spectrum is analysed for intensity a quantitative analysis results with some presumptions. These points are discussed in more detail on the following pages.

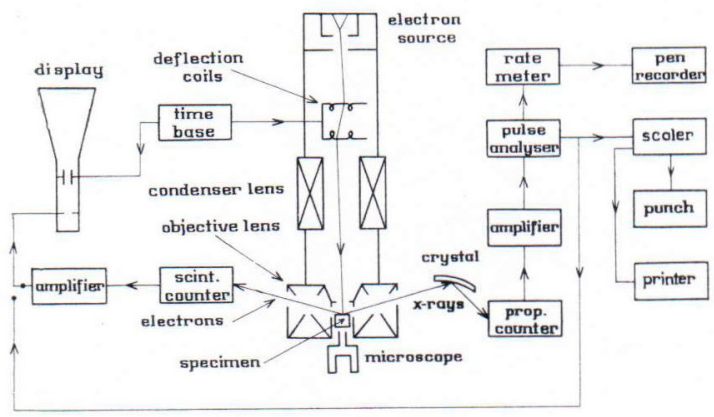

Fig. 1. Schematic layout of an electron microprobe.

1) For further details the reader is referred to e.g. L. S. Birks: Electron probe microanalysis. 1963. Interscience Publishers.

\section{Correction terms}

In his thesis, Castaing (1951) presented the basic principles of the quantitative $\mathrm{X}$-ray microanalysis. According to his assumption, the ratio of the characteristic line intensities of an analysed element measured on the sample and on standard (pure metal) are with respect to the corresponding concentrations

$$
\frac{\mathrm{I}_{\mathrm{A}}}{\mathrm{I}(\mathrm{A})}=\mathrm{C}_{\mathrm{A}} \text {. }
$$

Castaing stressed the fact that the main reason for the simplicity of this relation is the absolute character of the measurements. He was able to prove that this relation is not strictly valid and that it can be used only as the first approximation. In order to get more exact results the following corrections must be applied:

- dead time correction

- background correction

- absorption correction

- fluorescence correction

- atomic number correction.

All these corrections are due to the physical nature of this analytical method.

\section{Dead time correction}

When measuring any kind of radiation the dead time of the counting system must be taken into account in handling the final results. The formula by which the actual number of pulses can be calculated is

$$
\begin{aligned}
\mathrm{n}^{\prime} & =\frac{\mathrm{n}}{1-\tau \mathrm{n}} \text { with } \\
\mathrm{n} & =\text { measured number of pulses } \\
\mathrm{n}^{\prime} & =\text { corrected number of pulses } \\
\tau & =\text { dead time of counting system in } \mu \text { secs. }
\end{aligned}
$$

If the acceleration voltage and the specimen current are kept reasonably low so that the number of the recorded pulses is less than $5000 \mathrm{c} / \mathrm{sec}$. this correction is $<1 \%$ with the expected dead time of $2 \mu$ secs. The slowest part in a recording system can be a proportional counter, preamplifier, amplifier etc. When the dead time of any part is too long some pulses are lost. The dead time of 
a counting system can be determined by using a doublepulse generator or by measuring the number of pulses as a function of the specimen current. The experimental measurements show e.g. that with a flow counter and LiF-crystal in a GEOSCAN electron probe microanalyser a number of $4000 \mathrm{c} / \mathrm{sec}$. with a $60 \mathrm{~m} \mu \mathrm{A}$ specimen current can be recorded with no significant loss of $\mathrm{X}$-ray quanta.

\section{Background correction}

The second correction to be made is the background correction. It directly affects the number of measured pulses. The total intensity which is recorded on any characteristic line of a known element consists of the following components :

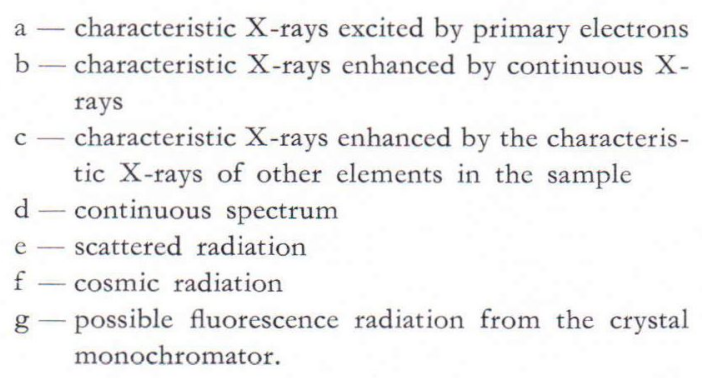

Normally the background is determined by measuring the intensities on the $2 \Theta$ readings which correspond to a small $\pm \triangle \Theta$ difference from the actual position of the maximum intensity. The mean value of these is used as a background and is subtracted from the total intensity. The background intensity can also be measured on the point of the maximum intensity by choosing a suitable sample with the identical mean atomic number and with a zero content of the element to be analysed.

\section{Absorption correction}

When measuring any radiation the common law for absorption

$$
\mathrm{I}=\mathrm{I}_{\mathrm{o}} \mathrm{e}^{-\mu \mathrm{k}}
$$

must always be taken into account. This means: when the radiation to be recorded goes through an intermediate layer its intensity falls exponentially.

Castaing (1951) based the absorption correction on experimental curves which were not well suited to multicomponent systems with variable acceleration voltages. Afterwards a large number of theories and experimental works arose, to establish the absorption method needed. Philibert (1962) proposed a correction term which is as follows:

$$
\mathrm{f}(x)=1 /\left(1+\frac{\varkappa}{\sigma}\right)\left[1+\mathrm{h}\left(1+\frac{\varkappa}{\sigma}\right)\right] .
$$

Philibert added the factor wh» which gives a small correction for the atomic number effect. The function $f(x)$ must be calculated for both the standard and the specimen. The correction procedure is given in Appendix II, p. 49. In the foregoing equation

$$
\begin{aligned}
\varkappa= & \frac{\mu}{\varrho} \cdot \operatorname{cosec} \Theta \text { with } \\
\frac{\mu}{\varrho}= & \text { mass absorption coefficient } \\
\Theta= & \text { X-ray take-off angle }\left(75^{\circ}\right. \text { in } \\
\sigma= & \text { Lenard's coefficient (depends } \\
& \text { acceleration voltage) } \\
\mathrm{h}= & 1,72 \cdot 10^{-6} \cdot \frac{\mathrm{A}}{\mathrm{Z}^{2}} \cdot \sigma \mathrm{V}^{2} \text { with } \\
\mathrm{A}= & \text { atomic weight } \\
\mathrm{Z}= & \text { atomic number } \\
\mathrm{V}= & \text { acceleration voltage. }
\end{aligned}
$$$$
\Theta=\mathrm{X} \text {-ray take-off angle }\left(75^{\circ}\right. \text { in GEOSCAN) }
$$$$
\sigma=\text { Lenard's coefficient (depends only on the }
$$

If $\sigma \mathrm{V}^{2}$ is regarded as a constant it follows

$$
\mathrm{h}=1,2 \cdot \frac{\mathrm{A}}{\mathrm{Z}^{2}} \text {. }
$$

Philibert's equation is quite easy to use. An approximation gives

$$
\mathrm{f}(x)=1-\frac{x}{\sigma} .
$$

When the correction is less than $5 \%$, this approximate value gives reasonably good results. Otherwise the long formula must be applied.

Duncumb \& Shields (1966) used Philibert's formula in principle. They took into account the critical excitation potential in deriving the absorption correction. They wrote Philibert's term $\sigma$ in the form

$$
\sigma_{\mathrm{c}}=\frac{2.39 \cdot 10^{5}}{\mathrm{E}_{\mathrm{o}}^{1.5}-\mathrm{E}_{\mathrm{c}}^{1.5}} \quad \text { with }
$$




\section{$\mathrm{E}_{\mathrm{o}}=$ incident beam energy in $\mathrm{kV}$ \\ $\mathrm{E}_{\mathrm{c}}=$ critical excitation potential in $\mathrm{kV}$.}

The final equation for correcting the absorption effect is

$$
\mathrm{f}(\varkappa)=1 /\left(1+\frac{\varkappa}{\sigma_{\mathrm{c}}}\right)\left(1+\frac{\mathrm{h}}{1+\mathrm{h}} \cdot \frac{\varkappa}{\sigma_{\mathrm{c}}}\right) .
$$

This formula lets the absorption fall to zero, as the difference between the acceleration voltage and the critical excitation potential is approaching zero, which is not allowed by Philibert's primary equation.

\section{Fluorescence correction}

When the sample to be analysed is bombarded by electrons the atoms are ionized 1 . by primary electrons,
2. by characteristic X-rays from other elements present and 3 . by continuous $\mathrm{X}$-ray spectrum. The total characteristic intensity measured is the sum of these three components and must be corrected in calculating the quantitative results.

$\mathrm{Characteristic}$ fluorescence In the Feanalysis of an $\mathrm{Fe}-\mathrm{Ni}$ alloy $(10 \% \mathrm{Fe}, 90 \% \mathrm{Ni})$ with $30 \mathrm{kV}$ accelerating voltage the intensity of the Fe $K_{a}$-line is increased by a factor greater than 1.3. Thus roughly $30 \%$ of the total intensity recorded is caused by the characteristic fluorescence of the $\mathrm{Ni} K$-lines.

There have been several theories and experimental measurements attempting to determine the fluorescence correction needed in quantitative analyses. The bacis term was presented by Castaing (1951). Later Reed $(1964,1965)$ modified Castaing's formula so that in addition to that of $K-K$ - fluorescence also the effect of $K-L-, L-K$ and $L-L$ - fluorescence can be determined. Reed's equation is as follows:

$$
\frac{\mathrm{I}_{\mathrm{f}}}{\mathrm{I}_{\mathrm{A}}}=0.5 \quad \mathrm{P}_{\mathrm{ij}} \mathrm{C}_{\mathrm{B}} \frac{{ }_{\mathrm{A}}-1}{{ }^{{ }_{\mathrm{A}}}} \mathrm{W}(\mathrm{B}) \frac{\mathrm{A}}{\mathrm{B}}\left[\frac{\mathrm{U}_{\mathrm{B}}-1}{\mathrm{U}_{\mathrm{A}}-1}\right]^{1,67} \frac{\mu_{\mathrm{B}}^{\mathrm{A}}}{\mu_{\mathrm{B}}}\left[\frac{\ln (1+\mathrm{x})}{\mathrm{x}}+\frac{\ln (1+\mathrm{y})}{\mathrm{y}}\right]
$$

where the symbols have the meanings

$$
\begin{aligned}
& \mathrm{I}_{\mathrm{f}} \quad=\text { fluorescence intensity } \\
& \mathrm{I}_{\mathrm{A}}=\text { intensity of primary radiation from the } \\
& { }^{\mathrm{P}_{K K}}=\mathrm{P}_{L L}=1 \text {, } \\
& \mathrm{P}_{K L}=0.24 \\
& \mathrm{P}_{L K}=4.2 \\
& \mathrm{C}_{\mathrm{B}}=\text { mass concentration of element } \mathrm{B} \\
& { }^{\mathrm{r}_{\mathrm{A}}}=K \text { absorption edge jump ratio of element } \mathrm{A}
\end{aligned}
$$

$\mathrm{W}(\mathrm{B})=K$-shell fluorescence yield of element $\mathrm{B}$ $\mathrm{A}, \mathrm{B}=$ atomic weights of elements $\mathrm{A}$ and $\mathrm{B}$ $\mathrm{U}=$ overvoltage ratio $\left(\mathrm{U}=\frac{\text { incident electron energy }}{\text { critical excitat. energy }}\right)$ $\mu_{\mathrm{B}}^{\mathrm{A}}, \mu_{\mathrm{B}}=$ mass absorption coefficients of element $\mathrm{A}$ $\mathrm{x}=\frac{\mu_{\mathrm{A}}}{\mu_{\mathrm{B}}} \operatorname{cosec} \Theta$ $\mathrm{y}=\frac{\sigma}{\mu_{\mathrm{B}}}$ with

$$
\begin{aligned}
\mu_{\mathrm{A}}= & \text { mass absorption coefficient of specimen for } \\
& K(B) \text { radiation } \\
\sigma & =\text { Lenard's coefficient } \\
\Theta \quad= & \text { X-ray take-off angle. }
\end{aligned}
$$

Reed's presentation seems to be complicated to use but fortunately he simplified it a great deal. The factor by which the result (see App. II) after the absorption correction must be multiplied is

$$
\begin{gathered}
\frac{1}{1+\gamma} \text { with } \quad\left(\gamma=\frac{\mathrm{I}_{\mathrm{f}}}{\mathrm{I}_{\mathrm{A}}}\right) \\
\gamma=\mathrm{C}_{\mathrm{B}} \mathrm{J}(\mathrm{A}) \mathrm{D} \frac{\mu_{\mathrm{B}}^{\mathrm{A}}}{\mu_{\mathrm{B}}} \cdot(\mathrm{g}(\mathrm{x})+\mathrm{g}(\mathrm{y})) .
\end{gathered}
$$

Reed presented the new functions of $\mathrm{J}(\mathrm{A}), \mathrm{D}, \mathrm{g}(\mathrm{x})$ and $\mathrm{g}(\mathrm{y})$ in tables and in graphs so that they are easy to apply. The effect of the fluorescence correction factor can be estimated calculating

$$
\gamma^{\prime}=\mathrm{C}_{\mathrm{B}} \mathrm{J}(\mathrm{A})
$$

and replacing $\gamma \approx \gamma^{\prime}$.

The product of the other terms in Reed's $\gamma$-function is normally near to unity. If the correction proves to be of a significant magnitude it is preferable to calculate the final correction following the more exact formula. The correction is largest when the exciting X-ray energy 
is slightly greater than the critical absorption energy of the element to be analysed and when the concentration of the exciting element is great. The correction concerning the light elements $\mathrm{Na}, \mathrm{Mg}, \mathrm{Al}, \mathrm{Si}$ etc. is normally very small and increases with increasing atomic number.

Continuous fluorescence. A most accurate correction term for continuous fluorescence was derived by Springer (1967). He proposed a rather long formula to calculate this correction. He also presented a table and some graphs to help this determination. The effect of this correction is demonstrated with examples. Finally it is concluded that the influence of this correction is mostly so small that it can be neglected.

\section{Atomic number correction}

After the previously presented corrections have been applied there is still one more to be calculated, the socalled atomic number correction. The atomic number effect arises when the specimen has an effective average atomic number different from that of the standard so that the balance between the mass penetration and the backscattering is different in the two targets.

Reed (1964) presented a term for correcting the atomic number effect. The factor by which the apparent concentration must be multiplied to obtain the true concentration is equal to

$$
\frac{\mathrm{S}_{1}}{\mathrm{~S}_{0}} \cdot \frac{\mathrm{R}_{0}}{\mathrm{R}_{1}} \text { with }
$$

$$
\begin{aligned}
\mathrm{S}= & \text { stopping power } \\
\mathrm{R}= & \text { backscattering loss factor } \\
& \text { subscript } 0 \text { means standard } \\
& \text { subscript } 1 \text { means specimen. }
\end{aligned}
$$

In multicomponent systems

$$
\begin{aligned}
& \mathrm{S}=\stackrel{\mathrm{i}}{\Sigma} \mathrm{c}_{\mathrm{i}} \mathrm{S}_{\mathrm{i}} \\
& \mathrm{R}=\Sigma \mathrm{i}_{\mathrm{i}} \mathrm{R}_{\mathrm{i}} \text {. }
\end{aligned}
$$

Springer (1966) derived a correction term following Reed. $\mathrm{He}$ presented graphs to determine $\mathrm{R}$ as a function of $\mathrm{E}_{\mathrm{c}} / \mathrm{E}_{\mathrm{o}}$ and tabulated

$$
\mathrm{S}=\frac{\mathrm{Z}}{\mathrm{A}} \ln \frac{2 \mathrm{E}}{11.5 \mathrm{Z}} \text { for elements with }
$$

atomic numbers from 1 to 92 . This offers an easy way to use this correction when needed.

The atomic number effect is greatest when the difference between the mean atomic numbers of the sample and the standard is large. When analysing silicate minerals with suitably chosen standards with other silicates or silicate glasses, this correction can also be neglected.

\section{Other corrections}

In the electron microprobe analysis there are many possibilities of making mistakes due to the physical nature of this method. Such effects which may require corrections are e.g. overlapping spectral lines and socalled satellite lines, variations in the composition of the standard used, contamination and element evaporation on the sample and the standard and errors in focusing the X-ray and the light optics.

The results can also be affected by the (mechanical) instrumental settings of the analysing system such as drifts in electronics, nonproportional behavior of the proportional counters and other recording devices, variations in the thickness of the metal or carbon coating and the surface effects due to the polishing of the sample. Normally all these can be avoided by carefully choosing the working conditions. -

The correction procedure presented above would seem to be very tedious work. The dead time and the background corrections must always be done in the quantitative work. Should the dead time of the counting system be known the first correction can be avoided. The absorption, fluorescence and atomic number corrections are the results of experimental determinations and estimated factors. So the final results always include an unknown factor which affects the accuracy but the magnitude of which is hard to deduct. Finally it can be concluded:

- The accuracy of an electron microprobe analysis cannot be stated with a single number. It depends greatly on the way of measuring and on the element to be analysed. The results of very small inclusions etc. are always less accurate than the ones obtained from large homogeneous samples.

- Normally the accuracy is not less than $1 \%$. It is lower if the corrections are large or the measured concentrations small.

- Because the calculations are time-consuming it is worth-while estimating the actual precision needed. 
- Even when the corrections are fairly large the estimations and the approximate values can be used with no loss in the accuracy of the final results.

\section{PART II}

\section{Quantitative analyses of some silicate minerals}

In the foregoing chapters, a short review of the theoretical considerations was given. This part deals with a series of measurements demonstrating how the calculations in an $\mathrm{X}$-ray microanalysis are performed, the accuracy in the final results etc. The main interest is centered on the absorption correction in order to show the magnitude of its effect. The fluorescence correction proved to be so small that it can be neglected. Finally a short series of analyses is performed to show the accuracy when determining the low concentrations in silicate minerals.

\section{The standards and the analysed samples}

The materials investigated in this work were collected as follows:

Standards:

$\begin{array}{ll}\text { - Quartz } & \mathrm{SiO}_{2} \\ \text { - Synth. corundum } & \mathrm{Al}_{2} \mathrm{O}_{3} \\ \text { - Hematite } & \mathrm{Fe}_{2} \mathrm{O}_{3} \\ \text { - Synth. sellaite } & \mathrm{MgF}_{2} \\ \text { - Fluorite } & \mathrm{CaF}_{2}\end{array}$

Since one purpose of the study was to lay stress on the standards, they were selected so that it was possible to analyse the five main components in the usual silicate minerals: $\mathrm{SiO}_{2}$, $\mathrm{Al}_{2} \mathrm{O}_{3}, \mathrm{Fe}_{2} \mathrm{O}_{3}, \mathrm{MgO}$ and $\mathrm{CaO}$.

\section{Specimens:}

- Silicate glass No. 28

$$
\begin{aligned}
& \text { — " » } 30 \\
& \text { — » » } \\
& \text { - » » }
\end{aligned}
$$

- Olivine, Marjalahti, Finland

- Enstatite, Kjörstad, Norway

- Eulite, Tunaberg, Sweden

- Diopside, Juva, Finland

- Tremolite No. 248/42

- " $\quad$ " $248 / 55$
- Hornblende $\gg 14987$
- Wollastonite, Lappeenranta, Finland
- Garnet, Virtasalmi, Finland

All the samples except the wollastonite had been previously analysed. The results of these analyses were regarded as the "correct» values with which the microprobe analyses were compared. With regard to wollastonite the »correct» value was the mean of three analyses presented in literature. The total iron was calculated as $\mathrm{Fe}_{2} \mathrm{O}_{3}$. This was caused by the fact that it is not possible to separate $\mathrm{Fe}^{+2}$ and $\mathrm{Fe}^{+3}$ ions in microprobe analysis.

The analyses were performed by using a microprobe, model GEOSCAN, which has been in use in our laboratory since December 1964. The different elements were analysed under the following conditions:

Si $20 \mathrm{kV}, 60 \mathrm{~m} \mu \mathrm{A}, K \alpha \quad$ (I)-line, Mica-crystal $\mathrm{Al} 15$ », »,$K \alpha$ (I) », ” »

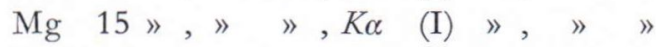
$\mathrm{Ca} 20$ ", " », Ka (III) ", " » $\mathrm{Fe} 25 », » », K \alpha_{1}$ (I) », $\mathrm{LiF}-$ »

Because these standards and samples proved to be homogeneous in a micron scale it was decided to record one series of $5 \times 20$ second on each. The five intensities were added together and the sum was used as the total characteristic intensity of the analysed element.

\section{Calculating the corrections and the results}

In calculating the results the procedure presented in Appendix II was performed. The dead time correction could be neglected due to the low counting rates. Having subtracted the background the first approximation was calculated 
by using both oxide and silicate standards (The fluoride standards are regarded as oxide standards). The mean h-values and the mean atomic numbers needed were calculated as follows:

$$
\begin{aligned}
\overline{\mathrm{h}} & =\Sigma \mathrm{c}_{\mathrm{i}} \mathrm{h}_{\mathrm{i}} \\
\overline{\mathrm{Z}} & =\Sigma \mathrm{c}_{\mathrm{i}} \mathrm{Z}_{\mathrm{i}} .
\end{aligned}
$$

Philibert's formula was applied in calculating the $\mathrm{f}(x)$-functions for standards and for specimens. As the mass absorption coefficients the rounded values from K. F. J. Heinrich's (1964) tables were used. The absorption correction was made as shown in Appendix II (paragr. 5) and thus the corrected results were obtained. Iteration was not used, since although it might increase the accuracy, in routine work the improvement is not worth the wasted time. The fluorescence correction was neglected. When calculating the weight- $\%$ for $\mathrm{Fe}_{2} \mathrm{O}_{3}$ also the atomic number correction was applied following Springer's procedure. The effect of this correction varies from $6.9 \%$ (Eulite) to $9.9 \%$ (Tremolite No. 248/55).

\section{Results}

The whole series of analyses is collected in Tables $1-5$ in which the following columns are presented:
Column 1. The first approximation and its difference (in weight-\%) from the »correct» value. The results were obtained by using the oxide standard.

Column 2. The first approximation and its difference (in weight-\%) from the "correct» value. The results were obtained by using the silicate standard (underlined).

Column 3. The result and the error after the absorption correction (oxide standard). In the $\mathrm{Fe}_{2} \mathrm{O}_{3}$-analyses the atomic number correction is included.

Column 4. The result and the error after the absorption correction (silicate standard underlined).

Column 5. The result of wet chemical analysis. Regarded as the "correct» value.

$\mathrm{SiO}_{2}$-analyses, Table 1 . The first approximation, the semiquantitative result calculated by using the silicate standard (col. 2) is more accurate than that obtained by using the oxide standard (col. 1). The error is smaller in the forementioned case. The deviation of these results, in except two of them, is in the negative direction. This is a common tendency also in some other series of analyses. The final results show that the silicate standard normally gives a slightly more exact analysis. On the other hand the absorption correction with the $\mathrm{SiO}_{2}$-standard seems to have been too great. This is shown

TABle 1

$\mathrm{SiO}_{2}$-analyses

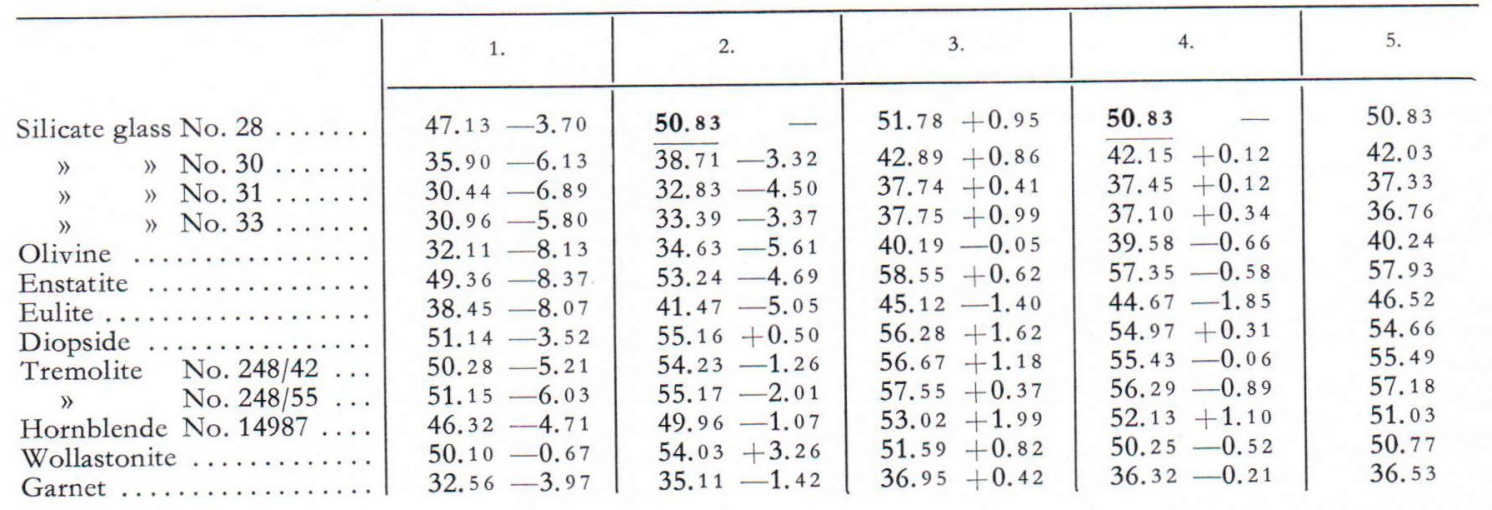


TABLE 2

$\mathrm{Al}_{2} \mathrm{O}_{3}$-analyses.

\begin{tabular}{|c|c|c|c|c|c|c|c|}
\hline & 1. & 2. & 3 & & 4 & t. & 5. \\
\hline Silicate glass No. $28 \ldots \ldots \ldots$ & $0.10 \quad-$ & 0.11 & 0.11 & - & 0.11 & - & - \\
\hline$" \quad "$ No. $30 \ldots \ldots$ & $16.70-1.13$ & 17.83 & 18.88 & +1.05 & 17.83 & - & 17.83 \\
\hline$"$ No. $31 \ldots \ldots$ & $19.19-1.95$ & $\overline{20.49}-0.65$ & 22.37 & +1.23 & $\overline{21.16}$ & +0.02 & 21.14 \\
\hline$" \quad "$ No. $33 \ldots \ldots$ & $18.27-2.53$ & $19.51-1.29$ & 20.94 & +0.14 & 19.74 & -1.06 & 20.80 \\
\hline Enstatite $\ldots \ldots \ldots \ldots \ldots$ & $0.62+0.45$ & $0.66+0.49$ & $0.74^{1}$ & +0.57 & $0.69^{1}$ & +0.52 & 0.17 \\
\hline Eulite $\ldots \ldots \ldots \ldots \ldots \ldots$ & $0.35+0.20$ & $0.38+0.23$ & $0.42^{1}$ & +0.27 & $0.39^{1}$ & +0.34 & 0.15 \\
\hline Diopside $\ldots \ldots \ldots \ldots \ldots$ & - $\quad-$ & - $\quad-$ & - & - & - & & 0.07 \\
\hline Tremolite No. $248 / 42 \ldots$ & $0.65-0.12$ & $0.70-0.07$ & 0.69 & -0.08 & 0.74 & -0.03 & 0.77 \\
\hline$» \quad \quad$ No. $248 / 55 \ldots$ & $0.58+0.36$ & $0.62+0.40$ & $0.65^{1}$ & +0.43 & $0.61^{1}$ & +0.39 & 0.22 \\
\hline Hornblende $14987 \ldots \ldots \ldots$ & $4.22-0.28$ & $4.51+0.01$ & 4.84 & +0.34 & 4.57 & +0.07 & 4. 50 \\
\hline Garnet.$\ldots \ldots \ldots \ldots \ldots$ & $6.65-0.32$ & $7.10+0.13$ & 7.44 & +0.47 & 7.01 & +0.04 & 6.97 \\
\hline
\end{tabular}

1) not shown in figure.

by the almost total positive deviations of the results. The values corrected for absorption are presented in Fig. 2, which shows the results as weight- $\% \mathrm{SiO}_{2}$ (probe) vs. weight- $\% \mathrm{SiO}_{2}$ (wet). If the final values obtained by different analytical methods were equal the results would lie on a straight line with a slope of $45^{\circ}$.

$\mathrm{Al}_{2} \mathrm{O}_{3}$-analyses, Table 2 and Fig. 3. The silicate standard gives considerably better results than the oxide standard. Also in this case

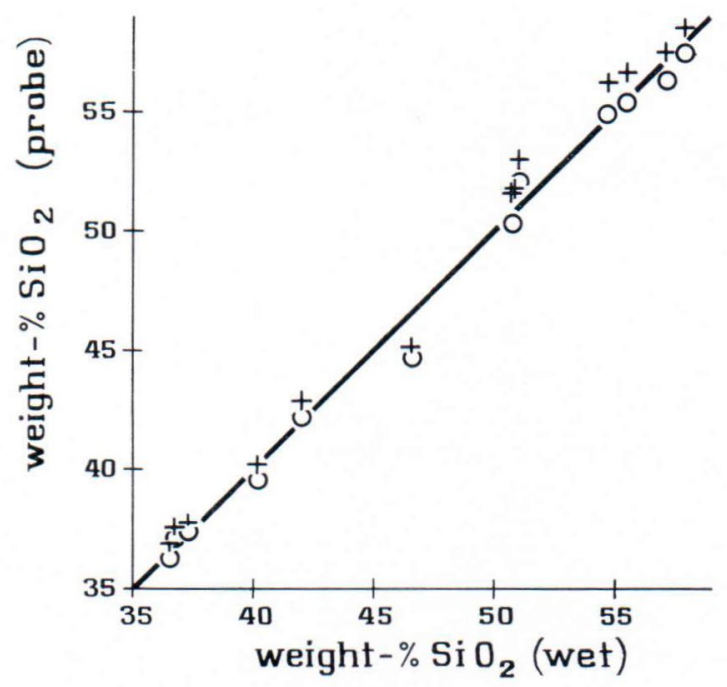

Fig. 2. Plot of weight- $\% \mathrm{SiO}_{2}$ (probe) vs. weight- $\% \mathrm{SiO}_{2}$ (wet). The results obtained by using silicate and oxide standards are indicated by $\mathrm{O}$ and + , respectively. the absorption correction concerning the oxide standard is too great. Regarding the small concentrations, the linear correlation between the characteristic line intensity and the analysed concentration would give more accurate results ( $c f$. p. 48). As to the detection limit in the Al-analyses, the silicate glass No. 28 gives a $0.1 \%$ content from nothing and a concentration of a same magnitude is not detected at all on diopside. Thus the concentration of $\mathrm{Al}_{2} \mathrm{O}_{3}$ which can still

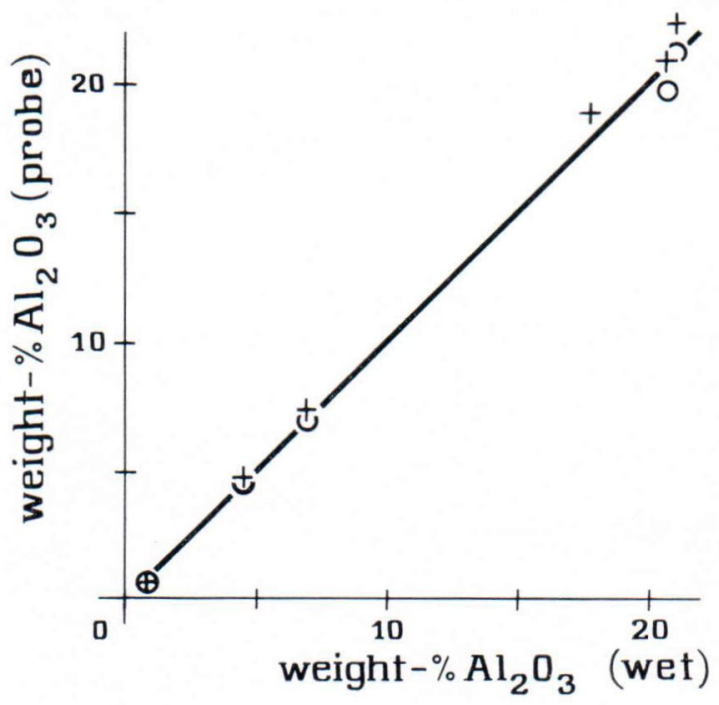

Fig. 3. Plot of weight- $\% \quad \mathrm{Al}_{2} \mathrm{O}_{3}$ (probe) vs. weight- $\%$ $\mathrm{Al}_{2} \mathrm{O}_{3}$ (wet). $\mathrm{O}$ and + as before. 
TABle 3

$\mathrm{Fe}_{2} \mathrm{O}_{3}$-analyses.

\begin{tabular}{|c|c|c|c|c|c|c|c|}
\hline \multirow[b]{2}{*}{ Silicate glass No. $28 \ldots \ldots \ldots$} & 1. & 2. & \multicolumn{2}{|c|}{3.} & \multicolumn{2}{|c|}{4.} & \multirow{2}{*}{$\begin{array}{c}5 . \\
16.83\end{array}$} \\
\hline & $13.30-3.53$ & $15.70-1.13$ & 15.42 & -1.41 & 15.79 & -1.04 & \\
\hline$" \quad "$ No. $30 \ldots \ldots$ & $7.56-1.75$ & $8.92-0.39$ & 8.82 & -0.49 & 9.01 & -0.30 & $\begin{array}{r}10.83 \\
9.31\end{array}$ \\
\hline$»$ No. $31 \ldots \ldots$ & $30.57-2.55$ & $36.10+2.98$ & 34.75 & +1.63 & 35.64 & +2.52 & 33.12 \\
\hline$" \quad " \quad N o .33 \ldots \ldots$ & $27.91-4.68$ & $32.96+0.37$ & 31.82 & -0.77 & 32.71 & +0.12 & 32.59 \\
\hline Olivine $\ldots \ldots \ldots \ldots \ldots$ & $10.82-1.96$ & $12.78-$ & 12.60 & -0.18 & 12.78 & - & 12.78 \\
\hline Enstatite $\ldots \ldots \ldots \ldots \ldots$ & $1.62-1.17$ & $\overline{1.91}-0.88$ & 1.90 & -0.89 & 1.93 & -0.86 & 2.79 \\
\hline Eulite...$\ldots \ldots \ldots \ldots$ & $43.88-5.06$ & $51.81+2.87$ & 49.12 & +0.18 & 50.65 & +1.71 & 48.94 \\
\hline Diopside..$\ldots \ldots \ldots \ldots$ & $0.03-0.73$ & $0.03-0.73$ & $0.03^{1}$ & -0.73 & $0.03^{1}$ & -0.73 & 0.76 \\
\hline Tremolite No. $248 / 42 \ldots$ & $3.09-2.26$ & $3.65-1.70$ & 3.60 & -1.75 & 3.70 & -1.65 & 5.35 \\
\hline$» \quad$ No. $248 / 55 \ldots$ & $1.43-1.74$ & $1.69-1.48$ & 1.69 & -1.48 & 1.71 & -1.46 & 3.17 \\
\hline Hornblende No. $14987 \ldots$. & $6.88-3.75$ & $8.10-2.53$ & 8.04 & -2.59 & 8.18 & -2.45 & 10.63 \\
\hline Wollastonite .......... & $0.03-0.43$ & $0.03-0.43$ & $0.03^{1}$ & -0.43 & $0.03^{1}$ & -0.43 & 0.46 \\
\hline Garnet ............. & $23.79-1.39$ & $28.09+2.91$ & 26.86 & +1.68 & 27.98 & +2.80 & 25.18 \\
\hline
\end{tabular}

1) not shown in figure.

be determined is hardly less than $0.2 \% \mathrm{Al}_{2} \mathrm{O}_{3}$ in this case.

$\mathrm{Fe}_{2} \mathrm{O}_{3}$-analyses are presented in Table 3 and Fig. 4. The semiquantitative results obtained by using the silicate standard are normally better than those obtained by using the hematite standard. The final results are not much better, When using the silicate standard the same precision can be obtained after the absorption correction as by using the hematite standard and applying

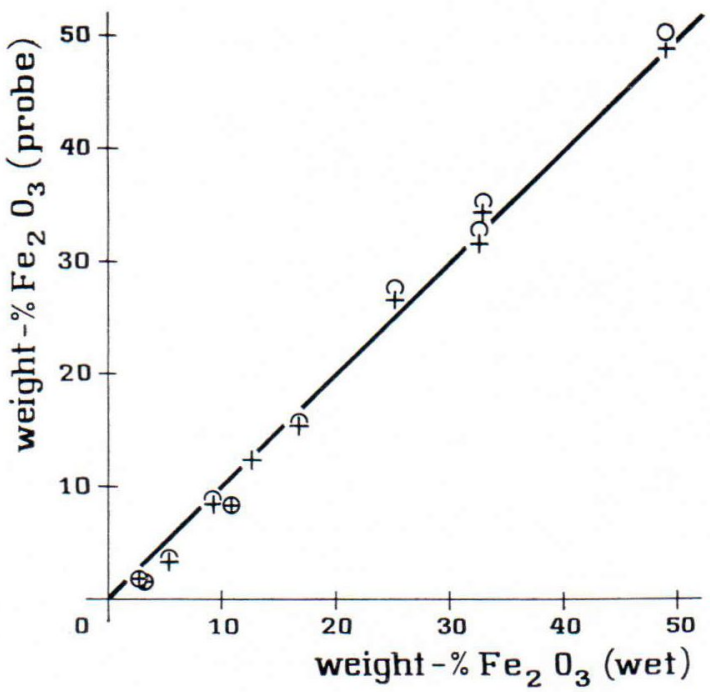

Fig. 4. Plot of weight- $\% \mathrm{Fe}_{2} \mathrm{O}_{3}$ (probe) vs. weight- $\%$ $\mathrm{Fe}_{2} \mathrm{O}_{3}$ (wet). $\mathrm{O}$ and + as before. both the absorption and the atomic number correction. The very long inter (extra) polation no doubt has a great effect on the final results especially in small concentrations.

$\mathrm{MgO}$ - and $\mathrm{CaO}$-analyses are shown in Tables 4 and 5 and in Figs. 5 and 6 respectively. The differences regarding the $\mathrm{MgO}$-analyses are nearly equal. In the $\mathrm{CaO}$-analyses the silicate standard gives more precise first approximations. As a rule the final results corrected for absorption are bet-

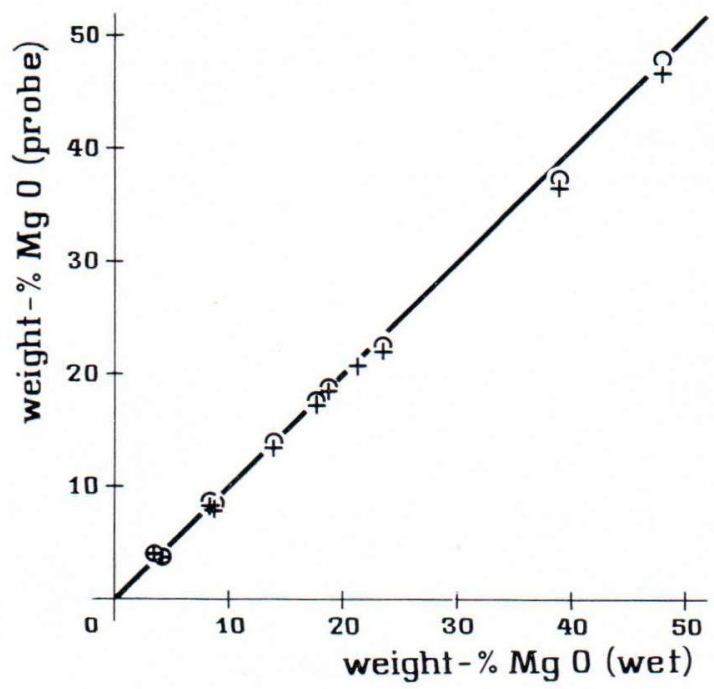

Fig. 5. Plot of weight- $\% \mathrm{MgO}$ (probe) vs. weight- $\%$ $\mathrm{MgO}$ (wet). $\mathrm{O}$ and + as before. 
TABLE 4

MgO-analyses.

\begin{tabular}{|c|c|c|c|c|c|}
\hline & 1. & 2. & 3. & 4. & 5. \\
\hline Silicate glass No. $28 \ldots \ldots$. & $8.01-0.52$ & $7.96-0.57$ & $8.14-0.39$ & $8.44-0.09$ & 8.53 \\
\hline$» \quad »$ No. $30 \ldots \ldots$ & $13.79-0.32$ & $13.70-0.41$ & $13.71-0.40$ & $14.19+0.08$ & 14.11 \\
\hline$»$ No. $31 \ldots \ldots$ & $7.97-0.39$ & $7.86-0.50$ & $8.58+0.22$ & $8.86+0.50$ & 8.36 \\
\hline$" \quad "$ No. $33 \ldots \ldots$ & $3.35-0.76$ & $3.31-0.80$ & $3.62-0.49$ & $3.72-0.39$ & 4.11 \\
\hline Olivine $\ldots \ldots \ldots \ldots \ldots$ & $48.52+0.44$ & $47.89-0.19$ & $46.81-1.27$ & $48.14+0.06$ & 48.08 \\
\hline Enstatite $\ldots \ldots \ldots \ldots \ldots$ & $39.39+0.42$ & $39.13+0.16$ & $36.52-2.45$ & $37.55-1.42$ & 38.97 \\
\hline Eulite ............. & $3.49-0.19$ & $3.44-0.24$ & $4.00+0.32$ & $4.16+0.48$ & 3.68 \\
\hline Diopside $\ldots . \ldots \ldots \ldots \ldots$ & $19.61+0.83$ & $19.36+0.58$ & $18.56-0.22$ & $18.86+0.08$ & 18.78 \\
\hline Tremolite No. $248 / 42 \ldots$ & $21.60+0.14$ & $21.46-$ & $20.83-0.63$ & $21.46-$ & 21.46 \\
\hline$» \quad$ No. $248 / 55 \ldots$ & $23.33-0.48$ & $\overline{23.18}-0.63$ & $22.19-1.62$ & $\overline{22.82}-0.99$ & 23.81 \\
\hline Hornblende No. 14987 .... & $17.65-0.23$ & $17.41-0.48$ & $17.39-0.50$ & $17.84-0.05$ & 17.89 \\
\hline Wollastonite .......... & $-\quad-$ & $-\quad-$ & - $\quad-$ & - - - & 0.29 \\
\hline
\end{tabular}

TABLE 5

$\mathrm{CaO}$-analyses.

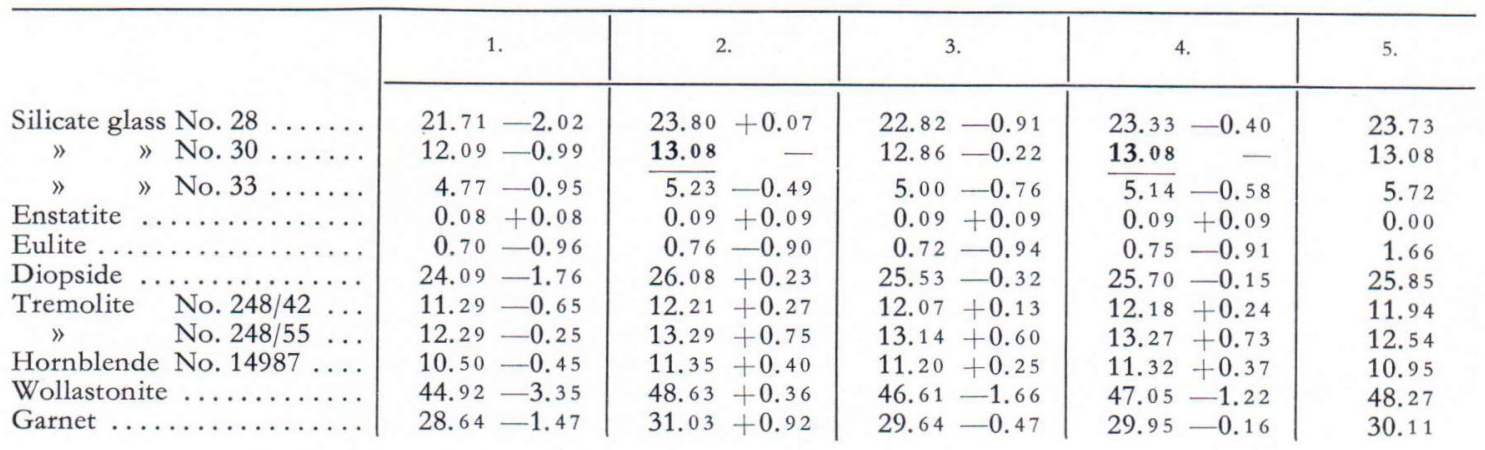

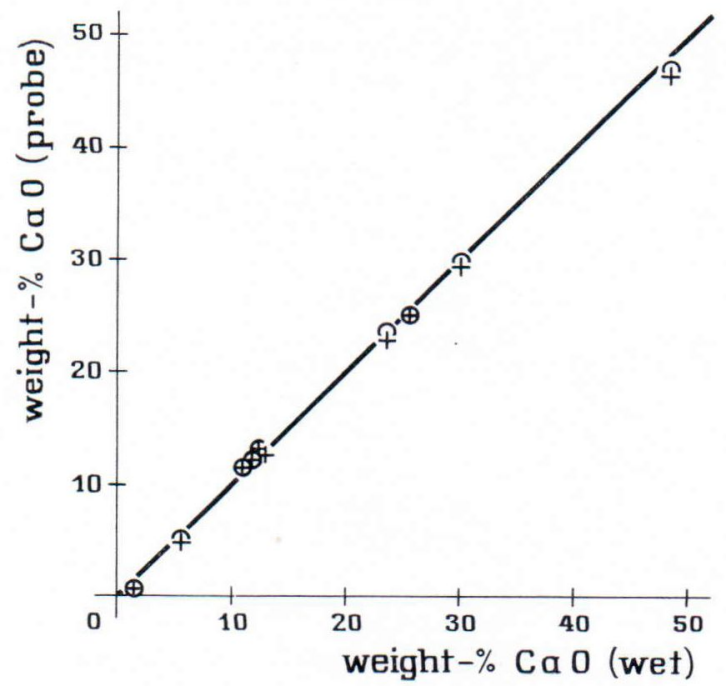

Fig. 6. Plot of weight- $\% \mathrm{CaO}$ (probe) vs. weight- $\%$ $\mathrm{CaO}$ (wet). $\mathrm{O}$ and + as before. ter when using the silicate standard than when using the »oxide» standard. On the basis of these analyses the detection limit of $(\mathrm{MgO}$ and $) \mathrm{CaO}$ in silicate minerals is estimated to be $0.4 \mathrm{MgO}$ and) $0.2 \% \mathrm{CaO}$ in this case.

The deviations between the sums of the analyses are very small, as shown in Table 6. The sum of an analysis is always a good control to the process but it does not ensure that the analysis is correct. An analysis of a single element might differ greatly from its »correct» value but the errors are compensated in calculating the final sums.

The precision of the results can be estimated as follows: If the accuracy is defined so that $2 / 3$ of the analyses are included, the limits presented in Table 7 are obtained. In this case, the cor- 
TABle 6

The sums of $\mathrm{SiO}_{2}, \mathrm{Al}_{2} \mathrm{O}_{3}, \mathrm{Fe}_{2} \mathrm{O}_{3}, \mathrm{MgO}$ and $\mathrm{CaO}$ calculated from the results obtained by using oxide standards (col. 1) and by using silicate standards (col. 3). Columns 2 and 4 show the differences from the expected correct value (col. 5. The sums of the forementioned oxides obtained by wet chemical methods).

\begin{tabular}{|c|c|c|c|c|c|}
\hline & 1. & 2. & 3. & 4. & 5. \\
\hline Silicate glass & & & & & \\
\hline $\begin{array}{l}\text { No. } 28 \ldots \ldots \\
\text { Silicate glass }\end{array}$ & 98.27 & -1.65 & 98.50 & -1.42 & 99.92 \\
\hline $\begin{array}{l}\text { No. } 30 \ldots \ldots \\
\text { Silicate glass }\end{array}$ & 97.16 & +0.80 & 96.26 & -0.10 & 96.36 \\
\hline $\begin{array}{l}\text { No. } 31 \ldots \ldots \\
\text { Silicate glass }\end{array}$ & 103.44 & +3.50 & 103.11 & +3.16 & 99.95 \\
\hline No. $33 \ldots \ldots$ & 99.13 & -0.85 & 98.41 & -1.57 & 99.98 \\
\hline Olivine $\ldots . \ldots$. & 99.60 & -1.50 & 100.50 & -0.60 & 101.10 \\
\hline Enstatite...$\ldots$ & 97.80 & -2.06 & 97.61 & -2.25 & 99.86 \\
\hline Eulite $\ldots \ldots \ldots$ & 99.38 & -1.57 & 100.62 & -0.33 & 100.95 \\
\hline $\begin{array}{l}\text { Diopside } \ldots \ldots \\
\text { Tremolite }\end{array}$ & 100.40 & +0.28 & 99.56 & -0.56 & 100.12 \\
\hline $\begin{array}{l}\text { No. } 248 / 42 \ldots \\
\text { Tremolite }\end{array}$ & 93.86 & -1.15 & 93.51 & -1.50 & 95.01 \\
\hline $\begin{array}{l}\text { No. 248/42 } \ldots \\
\text { Hornblende }\end{array}$ & 95.22 & -1.70 & 94.70 & -2.22 & 96.92 \\
\hline No. 14987 . . . & 94.49 & -0.51 & 94.04 & -0.96 & 95.00 \\
\hline Wollastonite .... & 98.23 & -1.56 & 97.33 & -2.46 & 99.79 \\
\hline Garnet ........ & 100.89 & +2.10 & 101.26 & +2.47 & 98.79 \\
\hline
\end{tabular}

rected results obtained by using both silicate standards and oxide standards are regarded as equals.

In the literature there are very few $\mathrm{X}$-ray microanalyses the accuracy of which can be determined. Smith (1966) presented microprobe analyses of olivines. His $\mathrm{FeO}$-analyses range e.g. $-2.13-+2.13$ weight- $\%$ from the accepted mean, $\mathrm{MgO}$-analyses $-3.49-+1.98$ weight- $\%$ and $\mathrm{SiO}_{2}$-analyses $-1.52-+0.81$ weight- $\%$, re-

\section{TABLE 7}

Estimated accuracy of the microprobe analyses presented in Tables $1-5$.

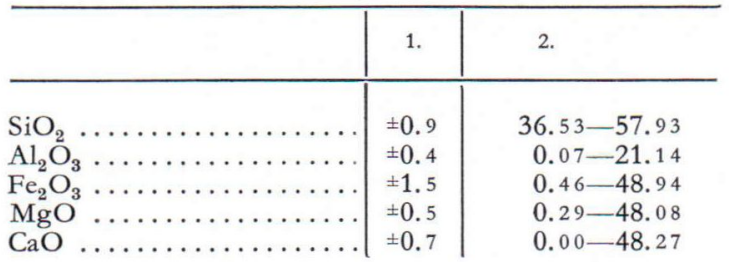

1. Accuracy of analysis (in percent)

2. Range of concentration (in weight-\%) spectively. Dahl (1969) reviewed the correction procedure for the electron microprobe analysis. In her paper there is e.g. analysis of some biotite grains performed by GEOSCAN-microanalyser. These results show the following deviations: $\mathrm{FeO}$ -0.6 weight- $\%, \mathrm{SiO}_{2} \pm 0.0$ weight- $\%, \mathrm{Al}_{2} \mathrm{O}_{3}$ +0.5 weight $-\%$ and $\mathrm{MgO}+1.3$ weight $-\%$.

In order to get an idea of the accuracy of a »normal» chemical analysis Table 8 is presented with silicate analyses of the U.S.G.S. new rock standards PCC -1 and BCR -1 . Both of these specimens were analysed by 26 analysts. Table 8 consists only of the results of the complete silicate analyses. If the determinations of single elements were submitted the deviations of the results would be much greater in many cases.

\section{TABLE 8}

The main components of the rock standards PCC - 1 and BCR - 1. Collected from »U.S. Geological Survey standards - II. First compilation of data for the new U.S.G.S. rocks» by F. J. Flanagan (1969).

PCC-1. 1.

$\begin{array}{llll}\mathrm{SiO}_{2} & \ldots & 41.87_{2}\end{array}$ $\mathrm{Al}_{2} \mathrm{O}_{3} \quad \ldots \quad 0.85_{6}$ $\mathrm{Fe}_{2} \mathrm{O}_{3} \quad \ldots \quad 2.844_{7}$ $\mathrm{FeO} \ldots . . .4 .94$ $\mathrm{MgO} \ldots . .43 .56_{2}$ $\mathrm{CaO} \ldots . .20 .53_{\star}$
2.

$41.23-42.4$

$0.21-1.86$

$1.48-5.00$

$2.98-6.12$

$42.49-45.9$

$0.20-0.75$
3.

$-0.64-+0.53$

$-0.65-+1.00$

$-1.37-+2.15$

$-1.96-+1.18$

$-1.07-+2.34$ $-0.33-+0.22$

$$
\text { BCR-1. }
$$

$\begin{array}{rrrr}\mathrm{SiO}_{2} \ldots & 54.48_{j} & 53.39-55.75 & -1.10-+1.26 \\ \mathrm{Al}_{2} \mathrm{O}_{3} \ldots & 13.65_{7} & 12.32-14.15 & -1.34-+0.49 \\ \mathrm{Fe}_{2} \mathrm{O}_{3} \ldots & 3.68, & 3.17-4.51 & -0.51-+0.83 \\ \mathrm{FeO} \ldots & 8.91_{2} & 8.33-9.45 & -0.58-+0.54 \\ \mathrm{MgO} \ldots & 3.28, & 1.93-3.81 & -1.35-+0.53 \\ \mathrm{CaO} \ldots & \ldots .95_{2} & 6.14-8.33 & -0.81-+1.38\end{array}$

1. Averages of the main constituents

2. Range of results

3. Deviations from the average in weight- $\%$

\section{MnO-analyses}

In this series the accuracy and the detection limit of a microprobe analysis were determined by analysing low concentrations in silicate minerals.

Nine specimens were selected whose $\mathrm{MnO}$ concentrations very from $0.02 \%$ to $3.64 \%$. As 


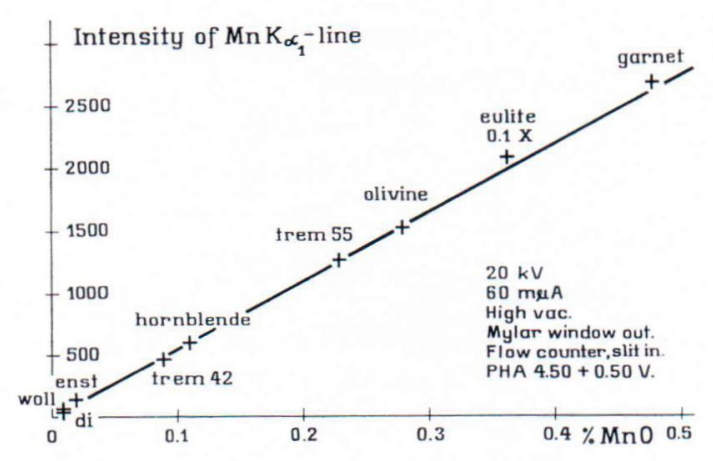

Fig. 7. Calibration curve of the $\mathrm{Mn} K a_{1}$-line intensity vs. weight- $\% \mathrm{MnO}$.

a standard an olivine was used with $0.28 \% \mathrm{MnO}$. The material had been previously investigated and proved to be homogeneous. The intensity of the $\mathrm{Mn} K \alpha_{1}$-line was recorded during a period of $5 \times 40$ seconds. The background was determined at a distance of $\pm 1^{\circ}$ from the $\mathrm{Mn} K \alpha_{1}$-line maximum. The results are shown in Fig. 7 and in Table 9. In column 4 the first approximation of $\mathrm{MnO}$-content is shown. It was calculated directly by using the characteristic line intensities from column 3. The absorption correction term was calculated following Philibert's formula. The fluorescence correction was applied when calculating the $\mathrm{MnO}$-content in eulite. In this case we had the $K \beta-K \alpha$-fluorescence. The factor of 0.1 was used to estimate the $K \beta-K \alpha-$ effect as proposed by Reed. Already the first approximation is sufficiently exact with samples other than eulite. The $f(x)$-terms are so equal that there is no great absorption effect. After applying the fluorescence correction the final result of eulite approaches the »correct» value. When small concentrations are analysed in silicate minerals there is a $1 \mathrm{in}$ e a r relationship between the concentration and the measured $\mathrm{X}$-ray line intensity (Fig. 7). The detection limit of manganese analyses can be concluded as follows:

A common definition of the point at which the $\mathrm{X}$-ray line is no longer distinguishable is

$$
\mathrm{I}-\mathrm{B}=3 \sigma_{\mathrm{B}}
$$

For example the background of diopside is equal to 357 .

$$
\begin{gathered}
\sigma_{\text {diop. }}=\sqrt{\mathrm{B}}=\sqrt{357} \approx 19 . \\
(\mathrm{I}-\mathrm{B})_{\text {diop. }}=47 \approx 3 \sigma_{\text {diop. }}=57 .
\end{gathered}
$$

In this case the intensity of the $\mathrm{Mn} K \alpha_{1}$-line corresponds to $0.01 \% \mathrm{MnO}$. Thus a concentration of $0.02 \% \mathrm{MnO}$ can be accepted as the detection limit of manganese in silicates.

\begin{tabular}{|c|c|c|c|c|c|c|c|c|c|}
\hline & 1. & 2. & 3. & 4. & 5. & 6. & 7. & 8. & 9. \\
\hline Olivine ... & 1872 & 342 & 1530 & - & 0.793 & - & - & - & 0.28 \\
\hline 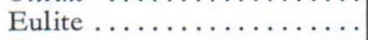 & 21455 & 540 & 20915 & 3.83 & 0.812 & 3.74 & 0.982 & 3.67 & 3.64 \\
\hline Garnet $\ldots \ldots \ldots \ldots \ldots$ & 3149 & 468 & 2681 & 0.49 & 0.798 & 0.49 & - & 0.49 & 0.56 \\
\hline Tremolite No $248 / 55 \ldots$. & 1625 & 362 & 1263 & 0.23 & 0.786 & 0.23 & - & 0.23 & 0.26 \\
\hline " No. $248 / 42 \ldots \ldots$ & 790 & 321 & 469 & 0.09 & 0.786 & 0.09 & - & 0.09 & 0.13 \\
\hline Hornblende No. 14987 . . . . & 897 & 293 & 604 & 0.11 & 0.787 & 0.11 & - & 0.11 & 0.122 \\
\hline Wollastonite .......... & 471 & 408 & 63 & 0.01 & 0.782 & 0.01 & - & 0.01 & 0.05 \\
\hline Enstatite $\ldots \ldots \ldots \ldots \ldots$ & 462 & 327 & 135 & 0.02 & 0.786 & 0.02 & - & 0.02 & 0.02 \\
\hline Diopside $\ldots \ldots \ldots \ldots \ldots$ & 404 & 357 & 47 & 0.01 & 0.785 & 0.01 & - & 0.01 & 0.02 \\
\hline
\end{tabular}

TABle 9

Electron microprobe analyses of $\mathrm{MnO}$-content in some silicate minerals. Olivine used as standard.

1. Total intensity measured

2. Background intensity

3. Total - background intensity

4. First approximation of $\mathrm{MnO}$-content

5. Absorption correction term $\mathrm{f}(\boldsymbol{x})$
6. $\mathrm{MnO}-\%$, corrected for absorption

7. Fluorescence correction term $1 /(1+\gamma)$

8. Final results, weight $-\%$ of $\mathrm{MnO}$

9. Results of wet chemical analyses, weight-\% of $\mathrm{MnO}$ 


\section{Conclusions}

The absorption correction is the most important when calculating the final results in X-ray microanalysis. The other corrections can be neglected in ro u t in e analyses when the accuracy needed is not of the highest possible class. Under favourable circumstances the absorption correction can be left aside as was shown by the $\mathrm{MnO}$ analyses. It is possible to perform a good semiquantitative analysis by using a known standard with a composition approaching that of the sam ple to be analysed. In case like this the measured line intensities directly give results accurate enough for e.g. mineral identifications.

In quantitative analysis the results obtained by using the oxide standards are slightly less accurate than the ones obtained with the silicate standards. At least the absorption correction must be applied in order to get quantitative results. When analysing common silicate minerals it is worth while using natural silicate standards or silicate glasses. If these are not available the simple compounds of the elements to be analysed can be used as standards with no great loss in the precision of the final results. The continuous electron bombardment of a synthetic standard material may lead to crystallization. This was noticed with one of the silicate glasses used in this work. When measuring very small concentrations, the 1 in e a $\mathrm{r}$ relationship between the intensity and the concentration can be used directly. An alternative is to apply previously determined calibration curves.

Table 7 shows that it is possible to obtain good accuracy in a very large concentration region. A comparison between Tables 7 and 8 suggests that the accuracy obtainable in the electron microprobe analysis is not worse than that in chemical methods.

The detection limits, $0.2 \%$ for $\mathrm{Al}_{2} \mathrm{O}_{3},(0.4 \%$ for $\mathrm{MgO}$ ) and $0.2 \%$ for $\mathrm{CaO}$, seem to be rather high. These are about ten times the values normally accepted. However, small concentrations of these elements are sometimes very difficult to analyse by wet methods. Futhermore, the procedure applied here is not the most suitable when determining the detection limit of an element.

In order to perform a quantitative analysis without making any corrections the standard must fit the two points: 1) The concentrations of all the elements should be almost equal in the sample and in the standard. 2) The values of the absorption functions $f(x)$ should be equal respectively. Furthermore, the preparing of the specimen should be equally done. In many cases these difficulties are too great to overcome in practice.

\section{Appendix I}

After the manuscript had gone to press a paper by T. R. Sweatman and J. V. P. Long was published dealing with »Quantitative electronprobe microanalysis of rockforming minerals». The effects of instrumental parameters and of wavelength shifts are discussed in detail. The different correction factors and their precision are examined separately. A comparison is made between the results obtained by using two microprobes with different X-ray take-off angles. Finally it is suggested that a computable correction method possibly serves as a preferable alternative to methods employing empirical calibration.

\section{Appendix II}

The measuring and the correction procedure needed in the electron probe X-ray microanalysis.

1. The intensity measurements

$\mathrm{N}^{\text {st }}=$ the characteristic line intensity from standard

$\mathrm{N}_{\mathrm{b}}^{\mathrm{st}}=$ the background intensity from standard

$\mathrm{N}^{\mathrm{x}}=$ the characteristic line intensity from sample

$\mathrm{N}_{\mathrm{b}}^{\mathrm{x}}=$ the background intensity from sample 
2. The dead time correction

$\mathrm{N}_{\mathrm{t}}=\frac{\mathrm{N}}{1-\tau \mathrm{N}}$ with

$\mathrm{N}_{\mathrm{t}}=$ the true intensity

$\mathrm{N}=$ the intensity recorded

$\tau=$ the dead time of the counting system

This correction is needed only with very high counting rates.

3. The subtraction of the background

$$
\begin{aligned}
& \mathrm{N}_{\mathrm{t}}^{\mathrm{st}}-\mathrm{N}_{\mathrm{b}}^{\mathrm{st}}=\mathrm{N}_{\mathrm{o}} \quad \text { (standard) } \\
& \mathrm{N}_{\mathrm{t}}^{\mathrm{x}}-\mathrm{N}_{\mathrm{b}}^{\mathrm{x}}=\mathrm{N}_{\mathrm{l}} \quad \text { (sample) }
\end{aligned}
$$

4. The first approximation of the final result

$$
\begin{aligned}
\mathrm{C}= & \frac{\mathrm{N}_{1}}{\mathrm{~N}_{\mathrm{o}}} \cdot \mathrm{C}_{\mathrm{o}} \text { with } \\
\mathrm{C}_{\mathrm{o}}= & \text { the concentration of the analysed ele- } \\
& \text { ment in standard. }
\end{aligned}
$$

5. The absorption correction in which Philibert's formula

$\mathrm{f}(x)=1 /\left(1+\frac{\varkappa}{\sigma}\right) \cdot\left[1+\mathrm{h}\left(1+\frac{\varkappa}{\sigma}\right)\right]$

or its approximate value

$\mathrm{f}(x)=1-\frac{x}{\sigma}$ is used.

In these terms

$$
\begin{aligned}
\mathrm{h} & =1.2 \cdot \frac{\mathrm{A}}{\mathrm{Z}^{2}} \quad \text { (tabulated) } \\
\sigma & =\text { Lenard's coefficient (tabulated) } \\
\varkappa & =\frac{\mu}{\sigma} \cdot \operatorname{cosec} \Theta
\end{aligned}
$$

The value of the $\mathrm{f}(x)$-function must be worked out for both the standard $\mathrm{f}\left(\varkappa_{\mathrm{o}}\right)$ and the sample $\mathrm{f}\left(\varkappa_{1}\right)$. The result $\mathrm{C}^{\prime}$ corrected for absorption is obtained, calculating

$$
C^{\prime}=C \cdot \frac{f\left(\varkappa_{0}\right)}{f\left(\varkappa_{1}\right)} \text {. }
$$

6. The fluorescence correction is applied by using Reed's term

$$
\gamma=\mathrm{C}_{\mathrm{B}} \mathrm{J}(\mathrm{A}) \mathrm{D} \frac{\mu_{\mathrm{B}}^{\mathrm{A}}}{\mu_{\mathrm{B}}}(\mathrm{g}(\mathrm{x})+\mathrm{g}(\mathrm{y}))
$$

or its estimate

$$
\gamma^{\prime}=\mathrm{C}_{\mathrm{B}} \mathrm{J}(\mathrm{A}) \text {. }
$$

The corrected result $\mathrm{C}^{\prime}$ is

$$
\mathrm{C} "=\mathrm{C} \cdot \cdot \frac{1}{1+\gamma}
$$

7. The atomic number effect is corrected by the procedure proposed by Springer. His graphs and tables are used in determining the $\mathrm{R}$ - and S-factors. The final result is

$$
C ",=C " \cdot \frac{S_{1} R_{o}}{S_{0} R_{1}}
$$

- If the corrections are very large at points 5,6 and 7 , an iterative procedure must be applied before making the next correction.

- Whenever possible the total sum must be calculated.

- In those cases in which silicate samples are handled with silicate standards it is possible to cut off the correction procedure after the absorption correction.

Acknowledgements - The author wishes to express his gratitude to Prof. Antti Siivola and to Dr. Atso Vorma for the many critical discussions and to Miss Karin Dahl for drawing the graphs.

\section{REFERENCES}

Castaing, R., 1951: Application des Sondes Electroniques a une Méthode d'Analyse Ponctuelle Chimique et Cristallographique. - Thesis, 1951. O.N.E.R.A. Publ. No. 55.

DAHL, M., 1969: Standards and correction methods used in electron microprobe analysis of biotites, amphiboles pyroxenes and plagioclases. - N. Jb. Miner. Abh. 110 (2), pp. $210-225$.
Duncumb, P. and Shields, P. K., 1966: Effect of critical excitation potential on the absorption correction. The electron microprobe. Ed. by McKinley, Heinrich and Wittry (1966), pp. 284-295.

FlanaGan, F. J., 1969: U.S. Geological Survey standardsII. First compilation of data for the new U.S.G.S. rocks. - Geoch. Cosmoch. Acta. 33 (1), pp. 81120. 
Heinrich, K. F. J., 1964: Mass absorption coefficient tables for microprobe analysis. - The electron microprobe. Ed. by McKinley, Heinrich and Wittry (1966), pp. 350-377.

Philibert, J., 1963: A method for calculation the absorption correction in electron probe microanalysis. $-\mathrm{X}$ ray optics and $\mathrm{X}$-ray microanalysis. Ed. by Pattee, Cosslett ans Engström. pp. 379-392.

REED, S. J. B., 1964: Some aspects of X-ray microanalysis in mineralogy. - Ph. D. Thesis, Cambridge.

- 1965: Characteristic fluorescence corrections in electron probe microanalysis. - Brit. J. Appl. Phys. 16, pp. $913-926$.
SмrтH, J. V., 1966: X-ray-emission microanalysis of rockforming minerals. II. Olivines. - J. Geology. 74 (1), pp. $1-16$.

Springer, G., 1966: Die Korrektur des Ordnungszahleffektes bei der Elektronenstrahl-Mikroanalyse. - N. Jb. Miner. Mh. 4, pp. 113-125.

- 1967: The correction for "continuous fluorescence» in electronprobe microanalysis. - N. Jb. Miner. Abh. 106 (3), pp. $241-256$.

Sweatman, T. R. and Long, J. V. P., 1969: Quantitative electronprobe microanalysis of rock-forming minerals. - J. Petrology. 10 (2), pp. 332-379.

Manuscript received, May 27, 1969. 